\title{
o grito que faz nascer a manhã (ou o amanhã)
}

Lucília Maria Sousa Romão

Universidade de Ribeirão Preto

Durante o mês de abril de 2004, o Movimento dos Trabalhadores Rurais Sem Terra (MST) iniciou uma série de ocupações, manifestações e atos públicos, cobrando do governo Lula agilidade na reforma agrária, medidas contra o desemprego e mudanças na política econômica. A divulgação do "abril vermelho" e a representação do ato de gritar abriram um novo capítulo do litígio discursivo em relação à reforma agrária; posições-sujeito entram em rota de colisão, convulsionadas pela ideologia e pelos sentidos que se constroem sob o signo da memória e da sua atualização. A partir de recortes colhidos em jornais impressos e eletrônicos, pretendo interpretar como o ato de gritar e sua interdição significam e como as representações de líder popular e de presidente derivam de posições em relação ao poder constituído, datadas pela conjuntura sócio-histórica, cuja materialidade é lingüística e histórica.

Durante el mes de abril de 2004, el Movimiento de los Trabajadores Rurales sin Tierra (MST) inició una serie de ocupaciones, manifestaciones y actos públicos, reclamando del gobierno agilidad en la reforma agraria, medidas contra el desempleo y cambios en la política económica. La divulgación del "abril rojo" y la representación del acto de gritar abrieron un nuevo capítulo del litigio discursivo en relación con la reforma agraria; posiciones sujeto entran en ruta de colisión, convulsionadas por la ideología y por los sentidos que se construyen bajo el signo de la memoria y de su actualización. A partir de recortes de periódicos impresos y electrónicos, pretendo interpretar qué significan el acto de gritar y su interdicción y cómo las representaciones de líder popular y de presidente derivan de posiciones en relación con el poder constituido, datadas por la coyuntura sociohistórica, cuya materialidad es lingüística e histórica.

"Um galo sozinho não tece uma manhã:/ ele precisará sempre de outros galos./ De um que apanhe esse grito que ele/ e o lance a outro; de um outro galo/ que apanhe o grito que um galo antes/ e o lance a outro; e de outros galos / que com muitos outros galos se cruzem/ os fios de sol de seus gritos de galo,/ para que a manhã, desde uma teia tênue,/ vá se tecendo, entre todos os galos.” João Cabral de Melo Neto aflora a coletiva tecelagem de gritos de galos, que, sob a cadência da manhã ainda escura, anunciam o sol e a claridão emergentes. Os gritos 
de galo, como as mobilizações populares, anunciam e constituem o raiar da manhã com rede de possibilidades e mudanças, que virão-a-ser.

$\mathrm{Na}$ certeza de que os sentidos e os atos de linguagem não brotam no sujeito como água na pedra, mas se constituem na/pela teia do interdiscurso, é possível dizer que os gritos desenham, no tecido da memória nacional, uma trama mais que presente: índios e negros gemeram seus gritos de indignação frente ao extermínio lento da senzala e da escravidão; imigrantes gritaram sua inserção nas lavouras e fábricas; camponeses, estudantes e mulheres afiaram o estribilho dos seus gritos em prol de direitos sonegados; torturados ensangüentaram quartéis com seus gritos de dor, enquanto, sob cifradas senhas, poetas cantaram seus gritos de rebeldia. O grito "Diretas-Já", em 1984, interrompia um itinerário sombrio de anos de chumbo. A plenos pulmões, operários disseram palavras de ordem em sindicatos com gritos que fizeram estremecer as fábricas e "Lula-lá" nada mais foi do que um grito de esperança a vibrar na garganta dos operários.

A partir dos anos 80, o país assiste ao nascimento do Movimento dos Trabalhadores Rurais Sem Terra (MST) como um coro de vozes que dá visibilidade aos párias do campo e busca forçar a entrada da reforma agrária na agenda nacional, recuperando os sentidos já ditos por outros movimentos de luta pela terra, a saber: Quilombos, Ibicaba, Canudos, Contestado e Ligas Camponesas (ROMÃO, 2002). A memória discursiva se atualiza, ancorada nos efeitos de justiça social, dívida histórica, mobilização dos excluídos e grito, pois para a população que teve a sua cidadania adiada desde o berço e que apenas é tratada como consumidora no circuito dado pelo capitalismo, resta a voz.

Do fundo do atoleiro-pântano da miséria e da injustiça social, faz eco o grito com as mesmas feições de pânico e horror que modelaram o rosto da personagem de Edward Munch. As pinceladas de assombro da obra pictórica se transmutam em gritos de indignação diante da barbárie constituída pela fome, exclusão da terra e desemprego. Do museu, o personagem do expressionismo alemão salta a olhar para os habitantes da periferia e grita o seu assombro. Na tela e na vida real, gritar é estratégia de se manter vivo, de amealhar visibilidade, de tornarse presente, de se inscrever no lugar da memória que sempre foi marginalizado pela classe dominante, de se fazer ouvir com aquilo que restou, ou melhor, com a última ferramenta que, do homem, lhe é própria e indomável: a voz. 
Assim, há, no ato de gritar, a memória discursiva, que faz funcionar os efeitos de indignação, resistência, luta e insubordinação ao poder constituído e que se materializa na língua, materialidade exemplar do litígio político e do confronto entre sujeitos com desiguais poderes, pois como Orlandi (1996, p. 138) aponta, é preciso levar em conta "o lugar social dos interlocutores e a desigualdade na distribuição dos conhecimentos". Os estudos da Análise do Discurso (AD) de matriz francesa, desenvolvidos a partir dos trabalhos de Pêcheux e Fuchs (1975), primam em postular que o sujeito não é livre nem fonte originária de seu dizer, mas uma posição discursiva dentro de uma conjuntura sóciohistórica, datada por contradições de classes, posição essa construída pela/ na filiação à teia da memória, dos sentidos já-ditos e/ou naturalizados, permitidos ou interditados para o lugar que o sujeito ocupa.

Voltando à rede histórica de gritos de galo, é possível dizer que ela entretece o nascer da manhã-Brasil, recolhendo no ar o clamor de um país desejoso de liberdade, justiça social e democracia para todos. Foi também uma somatória de protestos e mobilizações gritadas que constituiu (e ainda constitui) a trajetória do presidente Luis Inácio Lula da Silva, cuja biografia foi escrita com a voz rouca de tanto gritar ordens de mobilização e greve em portas de fábricas, em palanques improvisados em cima de peruas kombi. Desde cedo, Lula bem aprendeu que, sem grito, não sairia do nordeste pobre e não chegaria a São Paulo. No lugar de militante, percebeu que sem o megafone da causa operária e sem os gritos coletivos de seus iguais, não se tornaria emblemática presença diante dos patrões. A corda vocal calejada acordava outras cordas, como galo rouco de tanto chamar o nascimento da manhã.

$\mathrm{Na}$ inscrição discursiva de líder operário, os sentidos de protesto, ação coletiva, luta política, reivindicação eram legítimos, pois a ideologia os fazia parecer evidentes, possíveis e adequados. O lugar de onde ele enunciava era socialmente marcado por uma posição de classe compatível com o grito e com o ato de gritar. O protesto coletivo era peça de legalidade, legitimidade e ação estratégica. Alinhados a esses sentidos naturalizados para o sujeito na posição de líder sindical, vários movimentos populares fizeram funcionar essa zona da memória do gritar como metáfora de indignação, luta e resistência. O "Grito dos Excluídos", por exemplo, é um grande ato sempre realizado no dia 7 de setembro em várias capitais do país e que tem na Cidade de Aparecida (SP) a sua expressão mais forte. Lá, a Conferência Nacional dos Bispos do Brasil 
(CNBB), pastorais sociais e diversos setores da Igreja, intelectuais e representantes dos movimentos sociais fazem um grande ato político e engordam a fila da romaria dos trabalhadores. Reproduzo a seguir os princípios norteadores desse grito, escritos por Pe. Luiz Bassegio e Pe. Alfredo Gonçalves, ambos da Coordenação do Grito dos Excluídos no Brasil, que materializam as representações imaginárias que o ato de gritar evoca:

O Grito dos Excluídos não é um evento localizado no tempo e no espaço. Trata-se, antes, de um conjunto de atividades que convergem para uma determinada data de mobilização geral: o chamado "dia do Grito". Este, no Brasil, ocorre a 7 de setembro; na América Latina, a 12 de outubro. (...) No Brasil, o Grito dos Excluídos tem início em 1995. $\mathrm{Na}$ América Latina, pela primeira vez, em 1999. (...) Chega-se, assim, ao Grito propriamente dito. O que é? Antes de tudo, uma dor secular e sufocada que se levanta do chão. Dor que se transforma em protesto, cria asas e se lança no ar. De ponta a ponta do país ou do continente, o povo solta ao vento o seu clamor, longamente silencioso e silenciado. É um grito que ganha os ares, entra pelas portas e janelas, toma os espaços. Tem como objetivo unificar todos os gritos presos em milhões de gargantas, desinstalar os acomodados, ferir os ouvidos dos responsáveis pela exclusão e conclamar todos à organização e à luta. É o grito dos empobrecidos, dos indefesos, dos pequenos, dos sem vez e sem voz, dos enfraquecidos - numa palavra, o grito dos excluídos! ${ }^{1}$

Em consonância com esse grito dos excluídos, ao sujeito no lugar de líder sindical era permitida a denúncia do capital concentrado pelas multinacionais; era possível a narrativa sobre a falta de horizontes dos trabalhadores esmagados na linha de montagem; era legítimo lutar por aumento de salário, por direito de greve e por paralisação como forma de luta política. Também se materializava a equação simbólica entre o gritar, a quantidade de gritantes e o poder de fogo diante de negociações com o capital instituído dentro e fora das fábricas.

Depois de algumas tentativas inglórias, Lula chega ao cargo de primeiro mandatário do país. Tal fato é analisado como acontecimento discursivo por Indursky (2003, p. 110), posto que apresenta uma forte ruptura com as representações de presidente aceitas e construídas ao longo da história e memória nacionais:

1 Texto disponível na íntegra na página www.fortunecity.es/conjuntos/libertad/ 15/excluidos.htm 
Assistíamos a algo ainda não presenciado anteriormente, a algo ainda não nomeado na cena política brasileira. (...) um país que tinha sido sempre governado por bacharéis, por doutores ou militares, presidentes que representavam as oligarquias deste país, que representavam uma minoria dominante. E esta ruptura colocava, pela primeira vez, nesses 500 anos de história, na Presidência da República Federativa do Brasil, um filho do povo, um presidente sem instrução formal, que não possui nenhum diploma universitário, que atropela a língua em sua modalidade culta, que não fala nenhuma língua estrangeira, enfim, um operário, um torneiro mecânico que tem, na mão esquerda, apenas quatro dedos, marcando, dessa forma, indelevelmente, sua origem operária. E mais: um nordestino, que, longe de ser rico, é um retirante que migrou em um pau de arara para São Paulo e que passou fome. E, culminando tudo isto, um líder sindical, organizador de greves memoráveis que afrontaram a ditadura militar e que foi preso por desafiar a lei anti-greve então vigente no país, ditadura que veio justamente para "proteger o país do perigo vermelho, do comunismo". Um homem que se chama apenas Silva. (...) E esta ruptura certamente produz um acontecimento discursivo (...)

Realmente, na posse, o vermelho se estendeu do vestido da primeira-dama às esplanadas dos ministérios, ruas e espaços públicos em um espocar de estrelas cheias de esperança. Brasília ouviu a base dos gritos populares como uma explosão histórica de trabalhadores, operários, sem-terra, desempregados, que se viam representar no lugar de Lula e na voz de um presidente que se constituiu por sentidos contestatórios, rebeldes e socialistas em uma história pessoal de resistência e tenacidade. Eleitores e simpatizantes, vindos de todos os cantos do país, fincaram a bandeira do PT no núcleo decisório da política nacional como re-presença de ruptura e sentidos novos, quiçá estrelados.

Mas os tempos são outros, é certo. Passado o primeiro ano de luade-mel com o poder, MST e movimentos populares potencializam críticas à política econômica e à reforma agrária do governo, adormecidas pela cantilena da demora e dos parcos investimentos sociais. Durante o mês de abril de 2004, marchas, atos públicos e ocupações deram relevo à Jornada de Luta do MST, que a grande mídia batizou de "abril vermelho"; mais de 140 ocupações pipocaram em estados do Nordeste, Centro-sul e Sudeste, colocando publicamente gritos ritmados pelos acordes de insatisfação e reivindicação, o que discursivamente provocou a reatualização dos mesmos sentidos e do mesmo lugar que constituíram Lula como líder sindical e articulador de massas. Nessa/dessa posição de gritante, João Pedro Stedile enunciou que 
O Abril Vermelho não é um roteiro de ocupações e invasões de terra, mas sim um movimento de mobilizações organizadas e que contará também com a participação de outras entidades da sociedade civil (...) é preciso aproveitar este primeiro de abril para envermelhar o Brasil. É preciso que os movimentos de massa ganhem novo ânimo e voltem às ruas para discutir um modelo alternativo para este país. O que nós queremos é aproveitar o mês de abril para preparar um grande primeiro de maio. Vamos partir para as estradas. Nem que seja em passeatas, calados, quietos em protesto contra o capital. ${ }^{2}$

Em entrevista concedida a jornalistas, em Três Lagoas (MG), o presidente comenta a declaração acima, afirmando que

a reforma agrária não vai ser feita no grito dos trabalhadores ou no grito dos que são contra. Ela vai ser feita respeitando a legislação vigente e no clima de harmonia que norteia o comportamento de meu governo.

Ao afirmar que a reforma agrária não "será feita no grito", Lula enuncia de um outro lugar, que não aquele do qual o sindicalista falava. Provoca uma ruptura com os sentidos que edificaram sua trajetória, interditando os sentidos nos quais sempre se alocou para traçar a sua cartografia discursiva e política. Na posição de presidente, alinhado pela ideologia ao poder dominante, certos sentidos são interditados, proibidos e/ou indesejáveis, tidos como inconvenientes, tornando-se necessário silenciá-los. Esse efeito de evidência e naturalização é o trabalho da ideologia, que interpela o sujeito em sujeito do discurso e recorta para ele um sentido como único possível de ser dito, como o mais seguro e transparente. Sobre tal conceito tão caro à Análise do Discurso, Tfouni (2003, p. 154) afirma que:

(...) a ideologia decorre do estado da luta de classes em conflito uma com a outra, e um processo de apagamento/identificação do sujeito de/ com um ou outro lugar dentro dessa luta, o que vai determinar as seqüências produzidas/esquecidas pelo sujeito. Assim, temos que a desigualdade, produto da luta de classes, está inscrita na língua (...)

Tendo postulado que é na pele da língua que se marca a inscrição dos lugares-sujeito derivados da luta de classes, é possível dizer que

\footnotetext{
2 Site Último segundo, http://ultimosegundo.ig.com.br/useg/brasil/artigo/ 0,1566258,00.html (31 de março de 2004)

${ }^{3}$ Folha de S. Paulo, A 11, dia 4 de abril de 2004
} 
'aquele que grita' é deslocado do lugar legítimo de protesto e reivindicação, silenciado como um outro que se opõe à "harmonia do meu governo", desarrumando uma suposta ordem e desestruturando aquilo que estaria seguramente controlado. O grito, inflamado pelo excesso e pelo descontrole do gritante, desarticularia a paz social, assegurada pela legislação e pelo aparato democrático do governo do Partido dos Trabalhadores (PT). Silencia-se aqui a equação simbólica de que a harmonia seria vitimada pelo ato de gritar. O imaginário, que coloca o presidente no lugar daquele que tem autorização para sentenciar sobre a reforma agrária, é o mesmo que o faz elaborar o ato de gritar de outra forma, como interdição e silenciamento.

Ao negar o grito, o sujeito no lugar de presidente sinaliza uma região tranqüila, quiçá consensual para a realização da reforma agrária, como se desapropriar latifúndios fosse sinônimo de prática marcada por negociação amigável, até harmônica. Tensão zero, diferenças de formações ideológicas zero, luta de classes zero! O efeito de cordialidade representa o governo que, cheio de boas intenções, faria naturalmente a distribuição de terra no país como a promover um evento social entre amigos e não entre gritantes. Assim, aquele que grita cava temores e tremores em áreas como a estabilidade econômica, a governabilidade, a ausência de riscos, "a harmonia do meu governo", enfim. Na sombra do depoimento de Lula, está construído um lugar de calma, paciência e espera, que se confronta com os sentidos já-ditos sobre o(s) grito(s) e o ato de gritar que o constituíram ao longo da luta sindical.

Em direção oposta ao motor da memória das mobilizações históricas, já narradas neste artigo, e na contramão da história do presidente, o sujeito aqui promove a emergência e o florescimento da passividade, recortando uma região da memória que faz circular outros sentidos possíveis, a saber: a ineficácia de gritar, a afronta dos gritos e a inutilidade da voz exaltada no coletivo, quiçá sua ilegitimidade. Não se trata de avaliar ou julgar o governo em questão, mas interpretar o lugar de onde Lula enuncia, sua migração de uma formação discursiva para outra, a interdição de alguns sentidos, o processo de interpelação ideológica em dois lugares diferentes e a zona da memória acionada pelo sujeito antes líder de massa, agora líder do governo.

Reforço aqui que o sentido é entendido como efeito, pois as palavras não têm um valor referencial em si mesmas e só podem ser interpretadas a partir de condições de produção determinadas por 
relações de poder e pela luta de classes e significadas pela historicidade. Conforme Orlandi (1996, p. 160): "Como o texto é um espaço, mas um espaço simbólico, ele não é fechado em si mesmo: tem relação com o contexto e com os outros textos".

Ainda na materialidade lingüística, a seqüência, na qual o sujeito faz sentido, "no grito dos trabalhadores ou no grito dos que são contra", funciona de modo a emparelhar e apontar semelhanças entre o grito e o gritar de trabalhadores e ruralistas. $O$ enunciado faz funcionar $\mathrm{o}$ efeito de igualar, não marcar diferenças e pasteurizar regiões desiguais de poder como se elas fossem afins; e, ao assemelhar os diferentes e desiguais, promove-se o discurso soberano e vitorioso da ordem e da lei, cujo efeito é justamente tratar todos os cidadãos como se eles fossem iguais e tivessem os mesmos direitos e deveres. Ora, sabe-se muito bem que os sentidos e os poderes não são distribuídos de maneira homogênea. Portanto, a tentativa de processar qualquer consenso entre sem-terras e ruralistas sabota as desigualdades, silencia a dialética em que senhores e escravos se movem, significam (-se) e escrevem sentidos. No fundo, tal retórica infantiliza a questão política da reforma agrária.

Para o sujeito-presidente, o grito dos excluídos, construído na/ pelas tramas do interdiscurso, se desloca da região de luta e reivindicação, deixa de ser narrado como estratégia coletiva e passa a ser um genérico, o grito de qualquer um e de todo mundo, inclusive dos ruralistas, que discursivamente sempre se alinharam à manutenção de privilégios e posses e que, diga-se de passagem, nada grita(ra)m por mudanças sociais ao longo da história do país, a não ser aquelas que aumentavam o rol de seus privilégios.

Desse modo, Lula se coloca no papel do mediador sensato, neutro, que preserva e cultua os ideários da democracia e da Lei, a despeito de quaisquer gritos. É preciso dizer que, em vários períodos da história nacional, sob a cifra do apelo à legalidade, à força legal e à manutenção da ordem, processou-se uma estratégia de apagamento dos movimentos sociais. Falar em ordem, progresso, harmonia e paz social re-configura essa rede de sentidos, que faz avançar o banimento do grito daqueles que (teimaram) e teimam em clamar por mudanças na estrutura de poder, deslegitimando-os e narrando-os como desordeiros, criminosos, bagunceiros ou loucos, para, por fim, endossar a sua prisão (ROMÃO, 2002, 2003; ROMÃO e TFOUNI, 2002) . 
Os lugares de sindicalista e presidente se movem determinados pelo nebuloso jogo das relações de poder e afetados pela filiação a regiões da memória discursiva. É certo que os sujeitos são e estão sujeitos aos sentidos que a ideologia lhes permite enxergar e enunciar, e isso direciona o que eles podem e devem dizer em consonância com o poder constituído e/ou em sintonia com os gritos, que racham frestas no mesmo poder. Também é possível sentenciar que não existe uma regularidade lógica e controlável para o sujeito, pois antes o grito, agora a negação do gritar.

Mais importante do que a cor do mês de abril é interpretar o movimento de sentidos, posições e discursos, diante do e no poder, cuja materialidade lingüística e histórica foi interpretada nos depoimentos do líder do MST e do presidente da República. Na orla em que a materialidade da língua e da história se tocam, é possível observar que o sujeito sempre enuncia do lugar marcado socialmente e que a ideologia autoriza ou interdita sentidos para o sujeito constituído na/pela teia da memória. No caso, memória de gritos de galos que sempre anunciam a manhã e que, no caso, tecem possibilidades ou interdições para o amanhã.

\section{Referências}

BASSEGIO, L.; GONÇALVES, A. Grito dos Excluídos- Elementos de Reflexão. Disponível em <http:/www.fortunecity.es/conjuntos/libertad/15/ excluidos.htm>. Acesso em: jan.2004.

INDURSKY, F. Lula lá: estrutura e acontecimento. In: Organon 35, v. 17, Revista do Instituto de Letras da Universidade Federal do Rio Grande do Sul, Porto Alegre, 2003.

MELO NETO, J. C. Obra completa volume único. Rio de Janeiro: Editora Nova Aguilar, 1994.

ORLANDI, E. P. A linguagem e seu funcionamento: as formas do discurso. Campinas: Editora Pontes, 1996.

PÊCHEUX, M.; FUCHS, C. Mises au point et perspectives à propos de l'analyse automatique du discours. Langages, n.37, p.7-80, Paris, mars 1975. Trad. Bras. GADET, F; KAK. T. (Org.). Por uma análise automática do discurso. Campinas: Editora da UNICAMP, 1975. 
ROMÃO, L. M. S. O litígio discursivo materializado no MST: a ferida aberta na nação. 2002. 310f. Tese (Doutorado) - Faculdade de Filosofia, Ciências e Letras da Universidade de São Paulo, Ribeirão Preto.

ROMÃO, L. M. S.; TFOUNI, L. V. Vejam, caros amigos: o litígio discursivo. Disponível em: <http://www.achegas.net>. Acesso em jan.2002.

ROMÃO, L. M. S. Tramas do discurso, luzes da memória. In: Organon 35 , v. 17, Revista do Instituto de Letras da Universidade Federal do Rio Grande do Sul, Porto Alegre, 2003.

STEDILE, J.P. Entrevista. Disponível em: $<$ http://www.ultimosegundo.ig. com.br/useg/Brasil/artigo/0,,1566258,00.html.> Acesso em mar. 2004.

SILVA, L. I. L. Entrevista. Disponível em: <http://www1.folha.uol.com.br/ folha/brasil/ ult96u59704.shtml> Acesso em abr. 2004.

TFOUNI, L. V. E não tem linhas tua palma: esquecer para poder lembrar. In: Organon 35, v. 17, Revista do Instituto de Letras da Universidade Federal do Rio Grande do Sul, Porto Alegre, 2003. 